\title{
Correction to: Spinal circRNA-9119 Suppresses Nociception by Mediating the miR-26a-TLR3 Axis in a Bone Cancer Pain Mouse Model
}

\section{Zhongqi Zhang ${ }^{1} \cdot$ Xiaoxia Zhang $^{1} \cdot$ Yanjing Zhang ${ }^{1} \cdot$ Jiyuan $\mathrm{Li}^{1} \cdot$ Zumin Xing $^{1}$ (i) $\cdot$ Yiwen Zhang $^{1}$}

Published online: 11 November 2019

(C) Springer Science+Business Media, LLC, part of Springer Nature 2019

Correction to: J Mol Neurosci (2019)

https://doi.org/10.1007/s12031-019-01378-w

The original version of this article unfortunately contained a mistake in Fig. 2.

The authors found some inaccurate information in the figure after repeated experiments. The correct figure is shown in the next page.

The online version of the original article 10.1007/s12031-019-01378-w

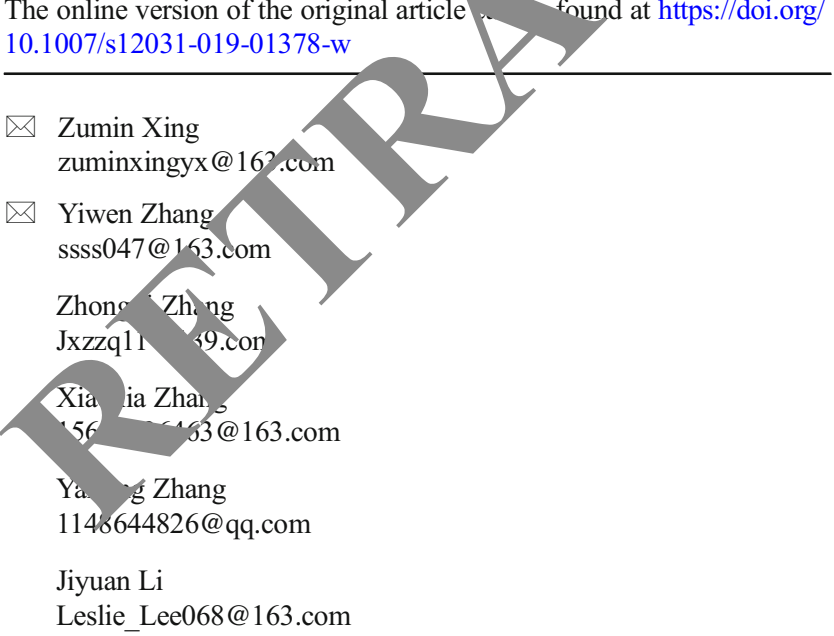

1 Department of Anesthesiology, Shunde Hospital of Southern Medical University, No. 1 Lunjiaojiazi Road, Shunde District, Foshan 528308, Guangdong, China 
a
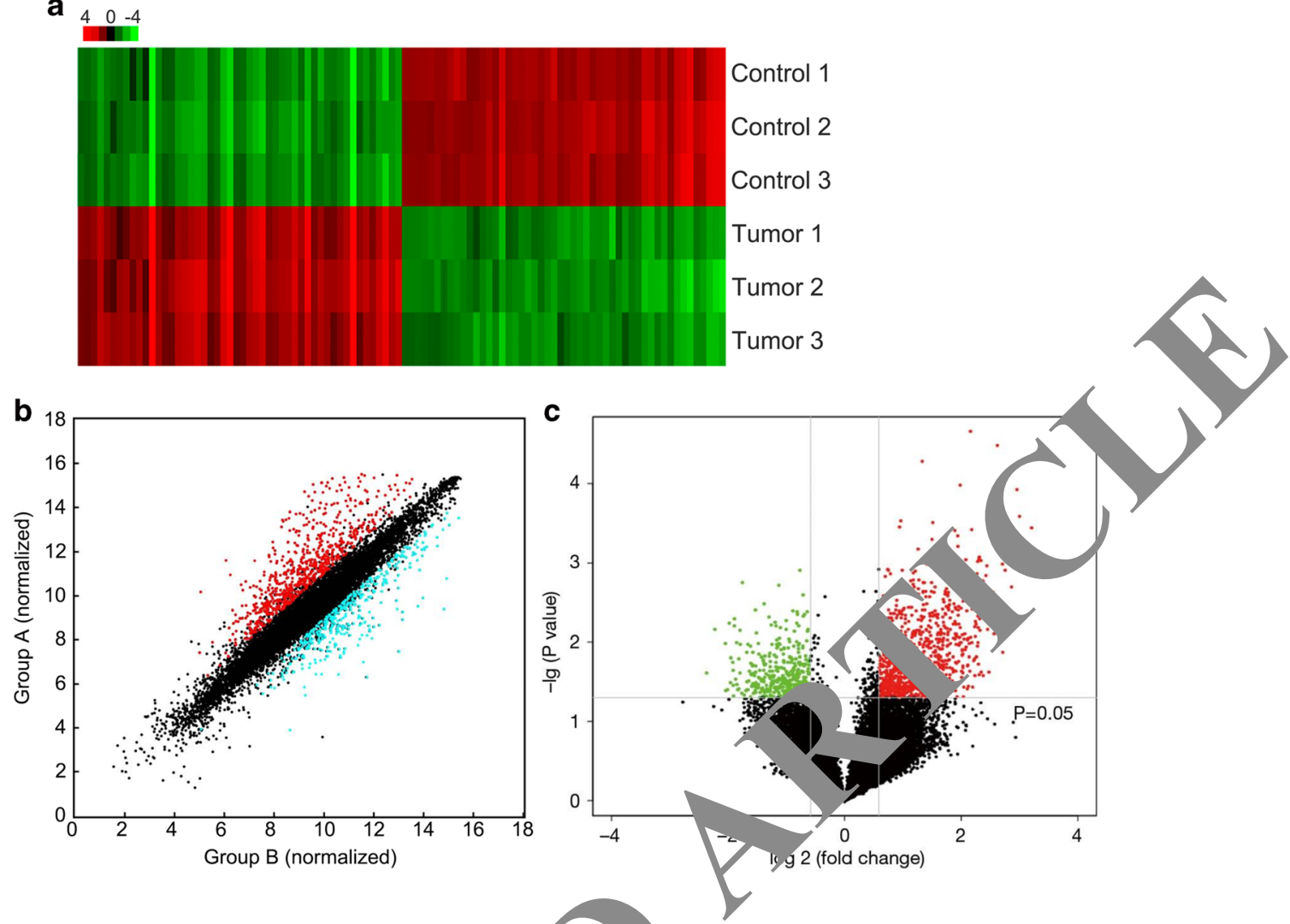

The original article has been corrected.

Publisher's Note Springer Nature remains neutral with regr d to jurisc tional claims in published maps and institutional affiliat on.

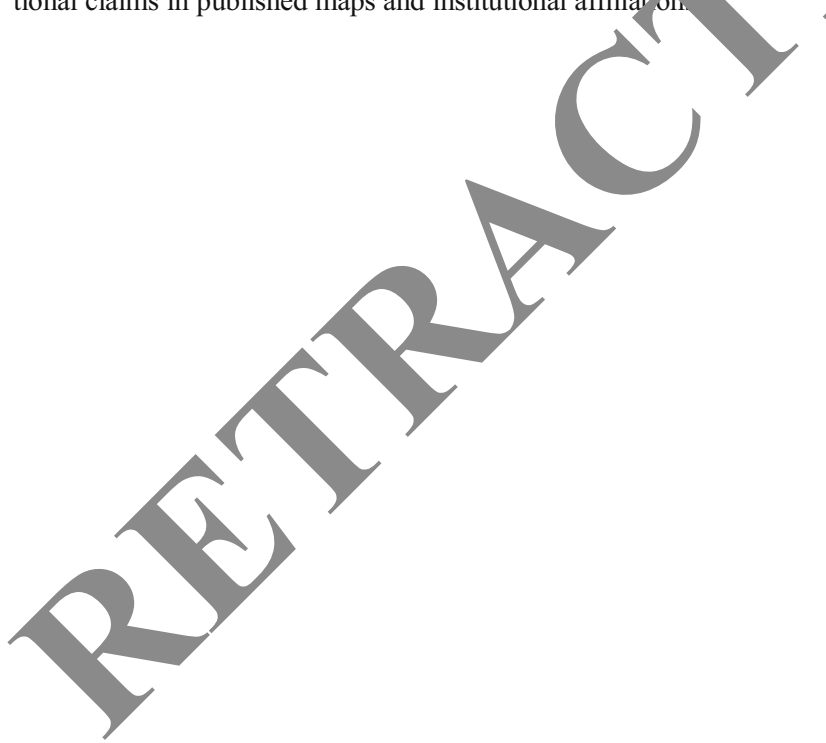

